\title{
Nietzsche e o caso Darwin
}

\author{
Eduardo Ribeiro da Fonseca* \\ Francisco Verardi Bocca**
}

Resumo: $\mathrm{O}$ texto analisa as possíveis intersecções entre as obras de Nietzsche e Darwin, considerando a recepção do darwinismo feita pelo primeiro e os problemas dessa leitura, partindo das próprias concepções teóricas de Nietzsche e avaliando as concepções do segundo a partir de uma leitura direta das obras do naturalista. Palavras-chave: Natureza, genealogia, vontade de potência, seleção natural, variação.

* Pontifícia Universidade Católica do Paraná, Curitiba, Paraná, Brasil.

ORCID https://orcid.org/0000-0003-4753-1864

Correio eletrônico: eduardorfonseca@uol.com.br

** Pontifícia Universidade Católica do Paraná, Curitiba, Paraná, Brasil.

ORCID https://orcid.org/0000-0001-6337-9263

Correio eletrônico: francisco.bocca@pucpr.br 
Fonseca, E. R.

O tema destas considerações é a recepção da obra do naturalista Charles Darwin (1809-1882) pelo filósofo alemão Friedrich Nietzsche (1844-1900). Como se sabe, o legado de Darwin surge na obra do filósofo alemão de modo enviesado, através de menções indiretas à obra do naturalista inglês. Cabe mencionar inicialmente que os livros A origem das espécies, de 1859, e a Descendência humana e a seleção sexual, de 1871, não são discutidos diretamente nos textos de Nietzsche. Os comentários do filósofo alemão fazem alusões apenas indiretas e fragmentárias à obra do naturalista inglês. Este último aspecto nos é atestado por Frezzatti Jr. em sua obra "Nietzsche contra Darwin" (2001, p. 21.): as referências "não perfazem um corpo coeso e organizado, pois estão espalhadas por vários textos do filósofo". Isso é significativo para compreendermos o contexto do surgimento do nome de Darwin na obra nietzschiana.

A polêmica antidarwinista que surge nos escritos de Nietzsche ocorre apenas pelo nexo dos temas darwinianos em relação aos interesses centrais da obra do filósofo e não por uma análise detida das posições do naturalista a partir de seus textos. Que ele combata certas ideias atribuídas a Darwin em seus textos, isto é claro e bem especificado pelo filósofo, mas que a letra de Darwin necessariamente corresponda à imagem que dela faz Nietzsche, isto já não pode ser afirmado tão facilmente.

Antes de levarmos adiante este argumento, lembremos que as críticas ao naturalista feitas pelo filósofo se deram em torno de temas como seleção natural, luta pela existência e sobrevivência, transmissão de características e outros correlatos. O que queremos indicar aqui são as condições e contradições pelas quais essa crítica se desenvolve na obra, bem como uma revisão das posições de Darwin, para entendermos até que ponto as divergências se justificam, e em que medida o próprio Nietzsche não estaria sendo às vezes um "darwinista" involuntário. $\mathrm{O}$ fato é que o primeiro vê o segundo como alguém que propaga o "ideal ascético" em suas ideias sem perceber 
que faz isso. Talvez o que mais incomode a Nietzsche, seja justamente a perturbadora associação entre ideal ascético e naturalização da vida que ocorre, na opinião dele, no "caso" Darwin.

\section{O contexto da crítica de Nietzsche a Darwin}

Desde o surgimento da obra do naturalista inglês, a naturalização da vida gera uma compreensível polêmica, em especial pelos seus resultados que contrariam o criacionismo e, também pela inovação de sua perspectiva e de seus resultados sobre o surgimento das espécies por evolução natural. A implicação mais importante para as conclusões de Darwin naquele momento guarda relação com o abandono das crenças criacionistas que estabeleciam em sua época o fixismo das espécies de acordo com um suposto plano divino, pois, segundo ele, não apenas as espécies se modificariam ao longo do tempo por seleção natural de características funcionais, mas, além disso, as variações não ocorreriam de acordo com um plano determinado de antemão por uma finalidade externa qualquer, mas por causas internas.

O fato é que Nietzsche teceu críticas contundentes a Darwin e ao darwinismo no interior de sua obra publicada, bem como também em seus fragmentos póstumos. Nos mais de sessenta escritos, aforismos e fragmentos onde aparecem esses temas darwinianos e darwinistas, ${ }^{1}$ menos de um quarto pertencem à obra publicada². Neles não há nada

\footnotetext{
1 "Darwiniano"/"darwinista": O primeiro termo se refere aos textos, às reflexões e opiniões do próprio Darwin, enquanto o segundo se refere aos usos e apropriações feitos por terceiros em relação à obra do naturalista inglês.

2 Falamos especialmente dos seguintes textos publicados pelo autor: DS/Co.Ext. I 7, 8, 9 e 11, KSA 1.193-227; FW/GC 99, 349 e 357, KSA 3.89/585/597. JGB/BM 14, 23 e 253, KSA 5.28/38/197; GM/, Prefácio 7, KSA 5.254; GD/CI, "Incursões de um extemporâneo", 14, KSa 6.120. E, da obra preparada pelo autor para publicação, citamos: EH/EH, "Por que escrevo livros tão bons" 1 e "Por que sou um destino" 8, KSA 6.298/373. Fora as citações mencionadas, existem muitos outros comentários sobre Darwin nos fragmentos póstumos do seu espólio. Anti-Darwin: fragmento póstumo 14 [123] e [133], 1888, KSA 13.303/315. Contra o darwinismo: fragmento póstumo 7 [25] 1886/1887, KSA 12.304, entre outros.
} 
Fonseca, E. R.

que aponte para uma possível interlocução direta com a obra de Darwin, no que esta poderia contribuir com argumentos em relação aos temas nietzschianos. Chama-nos a atenção que Darwin poderia justamente proporcionar a Nietzsche uma interlocução produtiva do ponto de vista de sua interpretação da história, da cultura, da fisiopsicologia e mesmo de seus pontos de vista éticos (suas críticas estão centradas principalmente nessa questão), que, em última análise, nos proporcionam um diagnóstico da cultura em relação aos quais as noções de Darwin poderiam oferecer além de um contraponto, também um ponto de apoio.

Em particular, se a obra de Darwin em si mesma parece de certa forma apresentar um caráter que corrobora as teses de Nietzsche sobre a Wille zur Macht, já que a noção de variação permite justamente um meio para se pensar o papel e a importância da singularidade no contexto de uma relativa normatividade dada na seleção natural, talvez devamos procurar alhures os motivos pelos quais surge a polêmica unilateral perpetrada contra o naturalista inglês. Estamos sugerindo que de certa forma, na maior parte das vezes, o nome Darwin está inadequadamente colocado no lugar do substantivo darwinismo.

Para que o leitor possa se situar acerca deste tema para o qual converge o nosso interesse, importa mencionar que Nietzsche discute Darwin, darwinismo, seleção natural, teoria da evolução, no contexto da interpretação do que seriam e quais as implicações da luta pela vida e da batalha pela sobrevivência dos organismos. Na verdade, as críticas presentes nos escritos de Nietzsche envolvendo esses temas repetem muitas vezes as de autores neolamarckistas alemães, por conta de não sabermos ao certo em que medida o filósofo teria lido as obras de Darwin. Sobre essa questão, recorremos novamente a Frezzatti Jr., para quem:

Se não temos certeza que Nietzsche tenha lido os livros de Darwin, o mesmo não ocorre com as obras de alguns neolamarckistas. Sem dúvida, esses estudos biológicos de tendência lamarckista realizados pelo filósofo 
alemão fundamentaram algumas páginas escritas contra o naturalista inglês (FREZZATTI, 2001, p. 23).

O fato é que as críticas de Nietzsche atacam o que talvez possa ser considerada a própria definição do darwinismo: a seleção natural como consequência da luta pela existência. As opiniões de Nietzsche sobre isso merecem uma atenção especial, mas, talvez em uma guinada exagerada de nossa parte, pensamos em que medida, talvez, nessas críticas, ao invés de uma recusa do pensamento darwiniano, não ocorra, pelo contrário, uma acentuação deste, no sentido de uma radicalização e um aprofundamento das teses do autor inglês em função do escopo cultural de Nietzsche e de suas preocupações genealógicas e fisiopsicológicas, no que também pode ser considerado, curiosamente, tributário de Darwin, na medida em que se pergunta acerca da origem das coisas e dos conceitos estabelecidos na cultura. Aqui seguimos apenas algumas indicações nesse sentido, mas tendemos a ver no seu antidarwinismo uma espécie de correção de rota do próprio darwinismo europeu, associada, possivelmente, a uma má interpretação das palavras do naturalista inglês através da leitura de comentadores que se apropriaram da obra do naturalista inglês de modo mais ou menos distorcido, ressaltando e extraindo consequências de questões que aparecem de modo diferente no contexto da obra de Darwin.

\section{Genealogia e moralidade}

Um aspecto que parece bastante frutífero para o argumento de que Nietzsche é de algum modo tributário a Darwin é a genealogia. Como observa Itaparica (2011, p. 70), Nietzsche critica certa "genealogia à inglesa" que associa o desenvolvimento dos traços originários da moralidade (entendida a partir de valores tais como a simpatia, o altruísmo e a preocupação com o bem comum) pelos seus efeitos benéficos para o conjunto das pessoas. Sabe-se que 
Fonseca, E. R.

Darwin e Wallace de fato percebiam no altruísmo uma vantagem da adaptação humana vinda por intermédio da linguagem e das formas culturais. Nietzsche critica esse privilégio dado ao altruísmo como uma concepção que ignoraria o caráter perspectivo das avaliações morais, transformando um valor meramente hegemônico em valor primordial, originário. Desse modo, a sua crítica assume que há uma construção histórica dos valores visando a sua própria consolidação como uma vontade de potência hegemônica não apenas no plano real, mas também no simbólico. Mas, temos dúvidas sobre se Darwin entende o altruísmo como simplesmente benéfico ou se ele o julga necessário.

Em Nietzsche, a genealogia apresenta duas características complementares: a) a descrição de uma origem a partir de um processo histórico, e b) a crítica como avaliação desse processo e dos seus resultados. Nisso, naturalmente, está pressuposta a reavaliação de valores em função da sua gênese. Nesse sentido, Darwin foi percebido como um dogmático involuntário pelo filósofo, pois estaria pressupondo que os valores cristãos da sua sociedade seriam uma consequência natural da evolução. Para Nietzsche, Darwin teria feito justamente uma genealogia interna aos valores sem considerar que possam ser apenas uma possibilidade entre outras, como uma representação social ligada a um período histórico determinado socialmente. Para Nietzsche, a crítica tem um propósito de transvaloração, o que não reconhece no pensamento darwiniano. Também em relação a isto temos dúvidas.

\section{Vontade de potência e moral do método}

Se tanto a genealogia quanto a questão da continuidade com a natureza parecem aproximar Nietzsche de Darwin, o que os afasta? Ora, a crítica ao darwinismo parte da compreensão do filósofo acerca da conservação do organismo que lhe parece implícito no elogio darwiniano do altruísmo. Para ele, a conservação seria um 
grau muito baixo da atividade da vontade de potência. Em Além do Bem e do Mal, por exemplo, Nietzsche diz que os homens de ciência, especialmente os fisiólogos, deveriam refletir melhor antes de estabelecer o instinto de autoconservação como originário: "Uma criatura viva quer antes de tudo dar vazão à sua força - a própria vida é vontade de potência" (JGB/BM 13, KSA 5.27). Neste sentido, a conservação seria uma consequência indireta do processo de exposição da vontade de potência como coisa orgânica. Esta interpretação da vida orgânica é, para Nietzsche, o fio condutor para pensar também o que é especificamente humano. Por isso, podemos considerar que em Nietzsche, como em Darwin, o homem pode ser visto, do ponto de vista fisiopsicológico, como um fenômeno natural específico e como sujeito de um querer.

Porém, em Nietzsche há uma questão metodológica importante, presente nos aforismos 22 e 36 de Além do bem e do mal, que se coloca em relação à vontade de potência. $\mathrm{O}$ filósofo coloca a questão em termos de uma "moral do método", o que significa, nesse caso, uma tentativa de sustentar a noção de vontade de potência em todos os planos da efetividade, sempre partindo dela e a ela retornando. Trata-se, nesse sentido, de uma interpretação global da existência que visa preparar as condições espirituais para o advento dos espíritos livres. Tal concepção parte do conceito de Trieb ${ }^{3}$ que, polissêmico, pode se referir tanto à atividade de um ponto de vista fisiopsicológico, cujo modelo é o arco-reflexo, quanto ao brotar das sementes e ação das chamadas forças naturais.

No que diz respeito à interpretação da vida orgânica como vontade de potência, Nietzsche pensa a partir de Schopenhauer e contra Schopenhauer - na verdade, poderíamos dizer, também a partir de Darwin e contra Darwin. Isto porque a noção de vontade de potência

3 Convém esclarecer que na doutrina da vontade de potência, a noção de Trieb não está circunscrita apenas ao âmbito científico (do arco reflexo até as forças). $O$ sentido específico explicita um processo contínuo de tendência ao aumento de potência. 
Fonseca, E. R.

substitui a noção schopenhaueriana da "vontade de viver" (Wille zum Leben) e também a noção darwiniana de "luta pela existência" como luta pela mera sobrevivência, preservação, autoconservação. Sobre isto, em "Crepúsculo dos Ídolos", o autor declara:

No que toca à famosa "luta pela vida", parece-me, por agora, mais afirmada do que provada. Ela ocorre, mas como exceção; o aspecto global da vida não é o estado de necessidade, a situação de fome, mas antes a riqueza, a abundância, e até a dilapidação absurda - onde se luta, luta-se por potência. (GD/CI, “Incursões de um extemporâneo", 14, KSA 6.120)

O comentário de Nietzsche não parece separar adequadamente o que ocorre no plano geral da natureza e o que ocorre no plano específico do indivíduo determinado, pois, ainda que a luta por potência se dê nos dois níveis, a abundância e a riqueza estão longe de serem realidades no cotidiano dos indivíduos. Mas, deixando esse comentário de lado, o que Nietzsche expressa no trecho acima seria de fato uma rejeição a Darwin? Talvez, pelo contrário, seja meramente uma reinterpretação e, eventualmente, uma radicalização do pensamento do naturalista e de suas consequências mais profundas e fecundas. Isto porque a leitura direta da obra de Darwin indica que a evolução por seleção natural não deve ser vista apenas pela ótica da mera conservação, mas também como uma estrutura afirmativa e de autossuperação de toda e qualquer vida orgânica no sentido de sua expansão e florescimento através das variações.

Seria o caso em que as formas de vida lutam, não apenas pela conservação da sua condição, mas por mais espaço para si, por mais domínio sobre o que as rodeia e isto cegamente em função de características herdadas e selecionadas espontaneamente pela sua plasticidade que proporciona mais domínio sobre o seu meio dentro de extensa medida de tempo. Nesse sentido, toda estabilidade seria apenas uma alteração momentânea do seu ritmo de expansão e busca por domínio no contexto natural. 
Há ainda em Darwin uma equivalência entre os processos naturais e os processos pelos quais os homens selecionam as características que lhes parecem serem úteis e agradáveis nos animais e plantas que criam. No mesmo movimento, o naturalista nos esclarece o papel da escala de tempo na qual se produzem as variações e também a seleção natural:

Assim como o homem pode produzir um bom resultado com seus animais domésticos e plantas acumulando diferenças individuais em uma dada direção, o mesmo ocorre com a seleção natural, mas muito mais facilmente, por ter um tempo incomparavelmente maior de ação (Darwin, 1875, p.41).

Nesse caso, a velocidade das variações em contraste com a seleção natural é a chave do processo e pode nos indicar o caminho de uma curiosa aproximação com Nietzsche. É precisamente a ideia de que toda vida orgânica seja vontade de potência que consideramos uma reinterpretação e uma radicalização involuntárias da doutrina de Darwin, ainda que usada contra o próprio Darwin, e que serviu a Nietzsche como instrumento para superar a valorização excessiva da conservação e da carência entendidos como fenômenos originários da chamada "luta pela existência", buscando, com isso, um modelo mais adequado para sustentar a afirmação da continuidade do homem com relação à natureza.

Além disso, Nietzsche, como Darwin, rejeita a teleologia, posto que não há em suas obras um plano prévio para a existência. Em Aurora, Nietzsche critica a interpretação tradicional da finalidade dos órgãos dos organismos em termos que praticamente repetem os de Darwin:

Os fins da Natureza -. Quem, como investigador imparcial, percorre a história do olho e das suas formas nas criaturas mais simples, e mostra o devir progressivo do olho, tem de chegar a este grande resultado: o de que o ver não é o propósito [ou seja, o fim, a finalidade] da gênese do olho, e de que, em vez disso, o ver apareceu quando o acaso já havia produzido o 
Fonseca, E. R.

aparelho. Um só exemplo destes: e os "fins" caem, como palas que caem dos olhos! (M/A 122, KSA 3.115).

Recorrendo à Genealogia da moral (cf. GM/GM, II, 11-13, KSA 5.309-318), entendemos que isto quer dizer, em primeiro lugar, que a "forma" (neste caso, o olho como "aparelho") precede a "finalidade", o "fim", o "sentido", a "utilidade", não é causado por ele. O ver não é a "causa final" do olho. A finalidade (o efeito útil) seria apenas o emprego ou o uso que é dado a uma forma e à sua atividade por outras forças, pulsões ou atividades que, como diz Nietzsche, a "reinterpretam" e "subjugam" num perpétuo devir. Assim, tudo o que resulta das variações aleatórias a que hoje chamamos variações genéticas, é assimilado por outras forças viventes (ou por outra força vivente) e é também apenas a posteriori adaptado a um determinado "fim" ou "utilidade" que, inicialmente, não lhe dizia respeito.

O novo que surge é "reinterpretado" por algo que já existia, é sujeito a um processo de "subjugação" que lhe confere um dado "sentido", uma "utilidade". A "finalidade", longe de ser uma forma de causalidade, é apenas essa "utilidade", e esta é "indefinível" na medida em que é o resultado de uma miríade de "interpretações" e "reinterpretações" anteriores (Cf. GM/GM, II, 13, KSA 5.316). São sempre novas sínteses a partir de sínteses antigas, máscaras sobre outras máscaras que, ao final, podem ser descritas como uma longa "sequência de processos de subjugação" (Cf. GM/GM, II, 12, KSA $5.313)$.

De modo semelhante, Darwin considerou que "em breve teremos que tratar as espécies como combinações inventadas [pelos homens de ciência] para maior comodidade" (Darwin, 2010, p. 455). Isto porque a questão genealógica e a escala de tempo necessária para o surgimento e a manutenção do que é complexo, de sua conformação, dependem ambas igualmente de o quanto a síntese de um conjunto de combinações de formas e instintos possa ser vantajosa para a vida, não apenas do ponto de vista de sua conservação, mas da ampliação 
de seu domínio no seu habitat natural e entre outros indivíduos, variedades e espécies.

Note-se que o "aperfeiçoamento" e a maior "perfeição" não são uma garantia de sobrevivência, mas sim apenas variações bem-sucedidas que se expressam e se reafirmam por centenas de milhares de anos e, mesmo assim, a tendência à complexidade não impede um fim abrupto de uma determinada linhagem de animais superiores. Darwin ressalta que existe a "concorrência" não apenas entre indivíduos de uma mesma espécie, mas também entre espécies do mesmo gênero, entre as que se sucedem e espécies diferentes, caso estejam concorrendo pelo domínio de um mesmo "habitat". A sobrevivência, nesse contexto, não é um objetivo, mas uma consequência da melhor adaptação e do domínio.

Tudo o que amplia as capacidades favorece a sobrevivência e torna os seres mais aptos. Assim, a seleção natural se baseia na opinião de que cada variedade ou espécie novas se formam e mantêm pelas "vantagens" adquiridas sobre as imediatamente concorrentes. Para Darwin as vantagens não são projetadas ou fazem parte de uma "unidade de plano", ou de uma "unidade de tipo". Ele parte da ideia de que inúmeras variações são produzidas e todas as variações espontâneas vantajosas tendem a ser conservadas pela sua eficácia prática no que concerne a resolver problemas colocados pela existência. No entanto, adverte: "A nossa ignorância com respeito às leis de variação é muito profunda" (Darwin, 2010, p. 155). Para o naturalista, é difícil estabelecer um regime de causa e consequência muito nítido no que tange às variações e às leis que estas seguem. Isto, porque, de um modo geral, somos ignorantes "sobre as relações afins que existem entre os seres organizados" (Darwin, 2010, p. 81).

Essas considerações pontuais obviamente não esgotam os problemas abordados, pois precisaríamos ainda nos dedicar de modo mais completo a outros pontos de vista, como a participação do acaso em tudo isso e, no caso humano, o papel da seleção sexual na cultura, 
Fonseca, E. R.

que é vista tanto por Nietzsche como por Darwin como o que define a diferença do mundo humano em relação ao mundo natural.

\section{Evolução para além da simples sobrevivência}

Para Darwin, "esta preservação das diferenças e variações individuais favoráveis, e a destruição das prejudiciais" deveria ser entendida como uma "seleção natural ou sobrevivência do mais apto" (Darwin, 2010, p. 40). No quarto capítulo de A origem das espécies esclareceu que alguns autores entenderam mal e por isso fizeram objeções ao termo "seleção natural". Alguns chegaram a pensar que a seleção natural induziria a variabilidade. Mas para ele, a seleção natural implicava apenas na preservação das inúmeras variações que de algum modo são benéficas para o indivíduo e sua espécie. "Estou convencido de que a seleção é o principal, mas não o exclusivo meio de modificação das espécies" (Darwin, 2010, p. 43), concluiu. Nesse caso há um mais além, embora nos pareça que isso não fosse exatamente bem compreendido por ele.

O naturalista postulou algumas possibilidades que poderiam explicar a evolução em harmonia com a noção de seleção natural, dentre elas a seleção sexual, mas também a ação direta do ambiente e a herança das características obtidas pelo uso e desuso, tal como já havia pensado Lamarck. Outra óbvia dificuldade foi a ausência de uma teoria genética adequada para lidar com os eventos em outra dimensão, pois, enquanto Darwin priorizava as influências externas, a genética passou a priorizar as internas, com consequências devastadoras para o evolucionismo.

Independente disso, Darwin acreditava que na Natureza havia uma incessante luta pela existência e que nessa luta atuava de forma poderosa e perpétua a seleção natural (Darwin, 2010, p. 233). Luta que poderia ocorrer entre indivíduos de uma mesma espécie, entre indivíduos de gêneros comuns e espécies diferentes, entre indivíduos de gêneros diferentes ou entre as espécies e o ambiente. Porém, 
segundo Bulmer (2005), ele considerava mais acirrada a luta entre indivíduos no interior de uma mesma espécie (2005, p. 133).

É sabido que Darwin recorreu, por analogia, à seleção artificial como meio para introduzir a seleção natural já que em várias passagens de $A$ origem das espécies, particularmente no quarto capítulo, no qual comparou o trabalho da seleção natural àquele realizado pelo homem com suas produções domésticas. Nessa situação o homem selecionava as características que lhe pareciam úteis e agradáveis dentre animais e plantas reproduzindo-as. Explicou a comparação nos seguintes termos: assim como o homem pode produzir um bom resultado com seus animais domésticos e plantas acumulando diferenças individuais em uma dada direção, o mesmo ocorre com a seleção natural, mas muito mais facilmente, por ter à sua disposição um tempo incomparavelmente maior de ação.

Segundo ele, as mudanças de condições de vida favorecem a seleção natural porque são mais propícias à produção de variações vantajosas. Essas variações se referem às diferenças individuais que teriam a mais alta importância porque são transmitidas hereditariamente, fornecendo o material sobre o qual atua a seleção natural. Ela resulta da combinação de fatores relacionados ao ambiente que automaticamente vão responder favorável ou desfavoravelmente à variação. Caso esta seja nociva, tende a ser eliminada. Caso seja benéfica, tende à persistência.

Pelo visto, a Evolução vai muito além da simples sobrevivência. Cremos que a insistência nesse termo é na verdade um problema de linguagem do que propriamente uma limitação de percepção do naturalista, que coloca a evolução em um quadro mais amplo, envolvendo disputa, imposição de força e a luta em si, de modo que a sobrevivência possa ser mais do que a decorrência da aptidão, mais do que um objetivo das espécies. Além disso, a seleção natural e a sobrevivência do mais capaz através da preservação de características favoráveis dependem também de determinadas configurações 
Fonseca, E. R.

populacionais. Darwin ressalta os efeitos benéficos relacionados ao aumento populacional do ponto de vista da variação:

Uma grande variabilidade - termo onde sempre são incluídas as diferenças individuais - será evidentemente favorável [à ação da Seleção Natural]. Um grande número de indivíduos, apresentando maiores possibilidades de variações vantajosas num determinado tempo, compensará uma menor variabilidade em cada indivíduo e será, acredito, um elemento muito importante para o sucesso. (Darwin, 2010, p. 49)

Note-se também a importância de considerarmos o papel dos instintos nesse mesmo contexto (variações vantajosas, seleção natural, adaptabilidade), considerando que, do ponto de vista de Nietzsche, a vontade de potência tem base instintiva e impulsiva. Portanto, inevitável que pensemos instintos e impulsos como uma chave conceitual para o diálogo possível entre Nietzsche e Darwin. De acordo com Darwin, os instintos são tão importantes para uma espécie quanto suas estruturas corporais e é bem possível que mesmo pequenas modificações no instinto possam ser úteis para uma espécie (Darwin, 2010, p. 19).

Ele acreditava que também as "qualidades mentais" dos animais domésticos estavam sujeitas a variações que poderiam ser herdadas. No oitavo capítulo de sua obra magna mostrou que os instintos de animais no estado selvagem poderiam variar ligeiramente. Acreditando que a seleção natural poderia agir sobre tais variações, considerou que ninguém questiona que os instintos sejam da mais alta importância para cada animal. Portanto, não existe nenhuma objeção para que, sob determinadas mudanças das condições de vida, a seleção natural acumule até certo ponto modificações do instinto que possam de algum modo ser úteis à espécie. Considerou também que em muitos casos o hábito e o uso e desuso provavelmente atuaram, numa clara assimilação das ideias de Lamarck. 
Darwin utilizou também o princípio da seleção natural para explicar a evolução de todos os seres vivos, inclusive do homem, incluindo suas faculdades morais e intelectuais. Abordou este aspecto da evolução em A descendência humana, de 1871. Nela, sugeriu que as faculdades morais e intelectuais do homem são derivadas em seus rudimentos dos animais inferiores. Ocorrem pela ação das mesmas leis gerais das quais derivou sua estrutura física (Darwin, 1871, p. 285). Nesse caso, todas elas sofreram variações que, ao final, foram vantajosas e selecionadas. Neste caso, por mais que a cultura nos pareça artificial frente à natureza, é ela mesma um fenômeno natural.

\section{Conclusão}

Relembremos os pontos cruciais da crítica de Nietzsche a Darwin: 1) a luta pela sobrevivência é uma exceção; 2) vida se caracteriza pela vontade de potência; 3) Não há teleologia no mundo orgânico; 4) A tese darwiniana é produto da moral cristã. Nietzsche contrapõe a Darwin o seu ponto de vista acerca da vontade de potência: 1) O aspecto geral da vida é a abundância e o desperdício, enquanto a luta pela existência é uma exceção, uma restrição momentânea (e até mesmo desejada pela vontade de potência); 2) A vida se caracteriza pela vontade de potência como vontade não de perseverar, mas de acrescentar, pelo que os impulsos (Triebe) tendem ao incremento da potência; 3) Não há teleologia no mundo orgânico, e, no mesmo sentido, faz uma crítica ao utilitarismo e à noção de progresso. A utilidade de um órgão não explica o seu surgimento. (Itaparica, 2011, p. 63.) 4) Nietzsche considera que as teses de Darwin contêm elementos da moral cristã (solidariedade, compaixão, gregariedade). (Itaparica, 2011, p. 64.) Desses pontos, o que realmente se apresenta à discussão a partir dos textos de Darwin?

Existem características inerentes à teoria da evolução natural das espécies de Darwin que apresentam elementos correlatos à noção de vontade de potência, ainda que não esclarecidos, e ainda que 
Fonseca, E. R.

tenha sido dada ênfase à expressão "luta pela sobrevivência". Esta expressão abriga aspectos que guardam relação menos com a noção de sobrevivência e mais com as noções de aptidão e êxito. Darwin reconhece que "luta pela sobrevivência" é uma expressão metafórica, que designa tanto ações de apoio e contextos de interdependência, quanto disputas territoriais, por alimento, ou por transmissão da herança sexual. (Darwin, 2010, p. 69.) A compreensão do termo "forte" como o mais apto (Darwin, 2010, p. 194.) também precisa ser destacada. Este pode ser inclusive individualmente fraco e pequeno como uma formiga. Mas, quem há de negar a capacidade conjunta das formigas para dominar um território sem competir diretamente com animais de grande porte, supostamente mais fortes e capazes? Depende da perspectiva que utilizarmos para fazer a abordagem do problema. E isso já está claro no conjunto da obra de Darwin. Nesse contexto a fraqueza significa meramente inaptidão, na medida em que determinados comportamentos e formas de organização podem ser mais ou menos proveitosos. Variando o contexto, variam também as necessidades e, por vezes, a capacidade adaptativa do mais fraco ou mais simples, pode ser um fator decisivo para a perpetuação da espécie.

Darwin trabalhou nos limites de seu conhecimento, a não ser para construir hipóteses reconhecidas assim apenas pelo seu grau maior de probabilidade. Um dos exemplos disso ocorreu quando ele modifica, ao longo das edições de sua obra magna, as suas opiniões acerca da importância das variações no contexto da evolução: "Nas edições anteriores desta obra [A Origem das espécies], provavelmente não atribuí o devido valor à frequência e à importância das modificações devidas à variabilidade natural" (2010, p. 196.)

Darwin ressalta que é difícil estimar o valor de pequenas modificações no contexto das grandes e dramáticas transformações ocorridas no contexto natural, mas nos lembra também que provavelmente até mesmo quando julgamos insignificante a influência 
do ambiente para a ocorrência de modificações, precisamos ter em mente que "toda pequena diferença individual assim como as variações mais acentuadas, que surgissem acidentalmente, devem ter uma causa". A seleção natural nesse contexto aconteceria da seguinte maneira: "É quase certo que se essa causa desconhecida atuasse de forma persistente, todos os indivíduos da espécie seriam igualmente modificados" (2010, p. 196).

Se a racionalidade puder ser vista por nós apenas como "a irracionalidade mantida sob controle" (Van Fraassen, 1989, p.172), poderemos avançar com relativa tranquilidade em meio às contradições envolvidas no grande problema da ciência e da vida. E se dentro dessa baixa expectativa, concedermos a Darwin que ele pôde apreciar de modo bastante autêntico e investigativo o que a história natural geológica e também o estado atual da natureza nos oferecem, partindo de um conhecimento obviamente limitado e conceitos provisórios, não podemos descartar que haja nisso uma legitimidade, que faz dela uma fonte notável de ideias e de novas possibilidades de pesquisa, envolvendo inclusive o abandono de suas teses em proveito de outras que nos pareçam mais autênticas.

Podemos dizer com certa tranquilidade que as leis científicas correspondem, de certa forma, às leis da natureza, ainda que pressuponham erros e modificações de teses e perspectivas frente a novas descobertas, desde que tenhamos diante de nós a clareza dos critérios adotados para aceitarmos ou divergirmos de certas posições. Não fosse assim, nem estaríamos discutindo Darwin a partir das críticas de Nietzsche. 
Fonseca, E. R.

\section{Nietzsche and the Darwin case}

Abstract: The text analyzes the possible intersections between the works of Nietzsche and Darwin, considering the reception of Darwinism made by the first and the problems of this reading, starting from Nietzsche's own theoretical conceptions and evaluating the conceptions of the second from a direct reading of the works of the naturalist.

Keywords: Nature, genealogy, will to power, natural selection, variation.

\section{Referências}

BULMER, Michael. The theory of natural selection of Alfred Russel Wallace. Notes \& Records of the Royal Society 59: 152-136, 2005.

DARWIN, C. On the origin of species by means of natural selection or the preservation of favoured races in the struggle of life. 6. ed. Chicago, Encyclopaedia Britannica, 1952 (Great Books of the Western World 49), 1875.

The descent of man and selection in relation to sex. Chicago: Encyclopaedia Britannica, 1952 (Great Books of the Western World 49), 1871.

. A origem das espécies e a seleção natural. São Paulo: Leopardo Editora. 2010 .

FREZZATTI JR., W. Nietzsche contra Darwin. São Paulo: Discurso Editorial/ Editora Unijui, 2001.

ITAPARICA, André L. M. Darwin e Nietzsche: Natureza e moralidade. In: Nietzsche e as Ciências. Org. Berrenechea et al. Rio de Janeiro: 7 Letras, 2011.

NIETZSCHE, F. Kritische Studienausgabe. Org. Giorgio Colli e Mazzino Montinari, 15 vols., Munique, DTV/ de Gruyter, $2^{\mathrm{a}}$ ed, 1999.

VAN FRAASSEN, B. Laws and Symmetry. Oxford: Oxford University Press, 1989.

Enviado: 03/04/2020

Aceito: 26/05/2020

208 | Cad. Nietzsche, Guarulhos/Porto Seguro, v.41, n.2, p. 191-208, maio/agosto, 2020. 